\title{
A fecundidade sob as lentes das preferências reprodutivas: um estudo para o continente asiático
}

\author{
Angelita Alves de Carvalho*
}

\begin{abstract}
GIETEL-BASTEN, Stuart Arthur; CASTERLINE, John; CHOE, Minja (ed.). Family demography in Asia: a comparative analysis of fertility preferences. Cheltenham, UK: Egard, 2018.
\end{abstract}

A obra Family demography in Asia: a comparative analysis of fertility preferences já sugere em seu título a que veio. Composto de uma coletânea de 24 artigos, 22 territórios e 55 pesquisadores, o livro apresenta, de forma detalhada e sistemática, insumos para a compreensão dos diferentes padrões de preferência reprodutiva na Ásia e, consequentemente, fornece evidências para refletir sobre as tendências futuras de fecundidade na região. Sua relevância perpassa, basicamente, por dois aspectos. Primeiro reside no fato de retratar, direta e indiretamente, a fecundidade de um número significativo de países asiáticos, com diferentes níveis de fecundidade, sendo as informações e as reflexões imprescindíveis ao futuro demográfico global, haja vista a relevância e magnitude do quantitativo populacional asiático. Já o segundo deve-se ao fato de o livro, de forma inovadora, debruçar-se sobre a compreensão da perspectiva individual para o delineamento dos níveis gerais de fecundidade, trazendo a lume as preferências reprodutivas e todos os temas que permeiam essa análise, como, por exemplo, tamanho ideal de família, desejo e intenções por filhos, preferência por sexo da criança, valor de ter filhos na sociedade, uso de contracepção e importância dos diferenciais socioeconômicos e demográficos.

O livro conta, no primeiro capítulo, com um artigo introdutório elaborado por dois de seus editores, John Carsterline e Stuart Gietel-Baster, que traz uma breve descrição dos

\footnotetext{
* Escola Nacional de Ciências Estatísticas (Ence), Instituto Brasileiro de Geografia e Estatística (IBGE), Rio de Janeiro-RJ, Brasil (litaacarvalho@yahoo.com.br; https://orcid.org/0000-0002-9342-4181).
} 
níveis de fecundidade dos países asiáticos, bem como relata os principais achados da coletânea. Os autores pontuam que a convicção predominante de que o elevado investimento nos filhos é crucial para seu sucesso, o custo de oportunidade de ter filho para os pais, especialmente para as mulheres, a busca constante por autossatisfação individual e o efeito transformador da melhoria dos meios de controle de natalidade são os principais condutores para a redução da demanda por filhos na região. Por fim, os autores apontam os méritos e o alcance do trabalho realizado e suas limitações, mencionando a necessidade de estudos de aspecto qualitativo sobre a temática. 0 segundo capítulo, de caráter teórico, apoia-se sobre a preferência por filhos homens no contexto asiático, revelando um enfraquecimento desse padrão em alguns países, perante as mudanças nas normas e valores de gênero e autonomia feminina. Ainda assim, o autor conclui que as preferências por sexo continuarão desempenhando um papel-chave na compreensão dos níveis e tendências futuras de fecundidade na região, agora, possivelmente, colaborando para a redução da fecundidade para abaixo do nível de reposição. Os outros 22 capítulos referem-se a artigos com análises empíricas acerca das preferências reprodutivas de um país/ região, abarcando os distintos territórios asiáticos. Nessa resenha esses trabalhos estão organizados segundo as regiões da Ásia, buscando, de forma bastante suscinta, apresentar os principais achados encontrados pelos autores.

A Ásia Oriental é a região com as menores taxas de fecundidade total (TFT) e engloba a análise de Japão, China, Taiwan, Mongólia e Coreia do Sul. 0 caso mais extremo é Taiwan, um dos países com menor TFT do mundo (inferior a 1 e com algumas províncias atingindo $0,73)$, em que o percentual acentuado de solteiros, os casamentos tardios e o adiamento da maternidade são apontados como os precípuos fatores responsáveis por esse cenário. Reduzidas também são as preferências reprodutivas, as quais se tornaram abaixo do nível de reposição ainda em 2000. Embora o número ideal de filhos esteja concentrando-se em 2 e 1, para a grande maioria das mulheres esses números são inatingíveis, haja vista o aumento no percentual daquelas sem filhos e das que terminam o período reprodutivo com apenas um. Na China, o cenário é parecido, contudo, a despeito da tendência de queda da fecundidade para níveis cada vez mais baixos, o número ideal de filhos sofreu alterações diferentes, passando de 2,2 em 1980 para 1,5 em 2000 e 1,9 em 2013 . 0 país ainda possui diferenças significantes entre as regiões rurais e urbanas, com maior preferência por filhos homens nas áreas rurais. A análise do Japão também revela uma baixíssima fecundidade e a existência de um elevado percentual de fecundidade não realizada. Todavia, mais do que o número ideal de filhos, que permanece ao redor da norma social de dois, a intenção por filhos é o indicador que capta melhor os níveis reais das preferências reprodutivas. O capital social e os distintos níveis de renda são relevantes para a determinação das preferências reprodutivas e, de forma distinta do que ocorre tradicionalmente nos países asiáticos, no Japão, atualmente, meninas são mais preferidas do que meninos. Nesses três países, apesar das diversas frentes de ação das políticas públicas implementadas, de incentivo à natalidade, mudanças econômicas, culturais e sociais acerca dos papéis e das 
expectativas de gênero e os desejos por um ou, mais frequentemente, dois filhos parecem estar desempenhando, cada vez menos, papel na definição das intenções na formação da família e nos níveis de fecundidade nesses países. Prevê-se uma contínua redução dos níveis de fecundidade, em que se fazem necessárias pesquisas qualitativas acerca dos motivos para o não alcance da fecundidade idealizada, das transformações nas relações de gênero e das políticas de cuidados e articulação de trabalho e família.

Por outro lado, o estudo da Mongólia evidencia uma exceção na Ásia Oriental, tanto por ser o único país com uma TFT acima do nível de reposição quanto pelo fato de essa taxa ter aumentado de 1,95 em 2005 para 3,1 em 2014. Esse comportamento diferenciado tem sido associado a uma recuperação da fecundidade, que foi adiada em décadas de crise e estaria sendo recompensada nesse momento, mas, sobremaneira, em função da cultura pró-natalista e do sucesso das políticas de incentivo à natalidade, que, se continuarem, servirão de estímulo para que o país continue com taxas elevadas de fecundidade.

A Ásia Central, analisada conjuntamente no artigo 6, inclui os casos do Cazaquistão, Uzbequistão, Turcomenistão, Tajiquistão e Quirguistão, em que os níveis de fecundidade variam entre 2,4 e 3,5 filhos por mulher. Há uma breve contextualização histórica da região, a qual tem grande importância para as características demográficas atuais dos países, notadamente as reduções de fecundidade observadas na década de 1990, após o colapso da União Soviética. Existem dois regimes de reprodução nesses países, que apresentam um padrão de número desejado de filhos de 2 e 4, com exceção do Cazaquistão, com concentração única em 2 filhos. Isso deve-se ao fato de que este país possui maior proporção da população de origens europeia e russa, em que as preferências de fecundidade são mais homogêneas e menores, enquanto os demais países possuem maior proporção da população concentrada em grupos étnicos, nos quais o número ideal de filhos é mais elevado. Destaca-se a predominância da preferência por filhos homens nessa região, especialmente no Tajiquistão. Tal característica possui forte evidência para a determinação dos níveis futuros de fecundidade, entretanto, a insuficiência de estudos detalhados sobre as preferências reprodutivas na região dificulta essa previsão.

Bangladesh, Índia, Nepal, Paquistão e Sri Lanka compõem a análise do sul da Ásia. 0 estudo para Bangladesh revela uma rápida redução de fecundidade e um tamanho ideal de família muito próximo à TFT de 2,3 filhos por mulher, embora prevaleça a fecundidade acima do ideal, a qual seria até $30 \%$ menor se nascimentos indesejados fossem evitados. Fatores como religião, mortalidade infantil e local de residência são determinantes para a preferência por filhos. Diferenciais regionais também são destaques no estudo da Índia, com uma TFT de 2,5, contudo variando de 1,6 a 3,2 filhos por mulher dependendo da região. Apesar do padrão jovem de casamento, observa-se redução da proporção de indianas que se casam antes dos 18 anos. Percebe-se diminuição no número de filhos desejados e na diferença entre fecundidade alcançada e desejada, com permanência das diferenças entre as áreas rurais e urbanas, principalmente no que tange à demanda por contracepção, que permanece elevada. Aumento da escolaridade, mudanças no padrão de casamento, 
preferência por sexo e uso de método contraceptivo poderão aumentar a idade para ter o primeiro filho e, consequentemente, reduzir os níveis de fecundidade do país. Paquistão, curiosamente, não segue a norma dos dois filhos desejados, ficando em um patamar em torno de quatro. Essa média é bastante estável, independentemente do local de moradia e sexo. A preferência por filhos homens e por mais de um filho homem está associada a tal resultado, em função não apenas da alta mortalidade, mas também porque esses meninos traduzem-se em estratégias de proteção para os pais na velhice.

O capítulo 15 analisa o Nepal, que desde 1960 possuía políticas de controle de natalidade, mas somente na década de 2010 é que a fecundidade alcançou o nível de reposição. Há diferenças étnicas e topográficas que contribuem para a existência de grandes diferenciais de fecundidade no país, em que, por exemplo, algumas regiões mais remotas vivenciam um aumento na fecundidade recente, mesmo com o declínio do número de filhos desejados. A preferência por filhos homens é um dos fatores responsáveis pelo aumento da discrepância positiva de fecundidade. 0 Sri Lanka, apesar de ter passado por rápida transição da fecundidade, experimenta um comportamento pouco comum, em que a fecundidade aumentou de 1,98 para 2,4 em 2012 e declinou para 2,2 em 2016. Essa tendência tem relação com o tsunami ocorrido em 2004 e com a guerra civil que assola alguns distritos, que parecem ter afetado as decisões reprodutivas e suas preferências por famílias maiores, bem como a adoção de políticas pró-natalistas. Outros fatores, como escolaridade, diferentes grupos étnicos e participação feminina no trabalho, possuem relação direta com o número de filhos desejados e a fecundidade realizada. Para ambos os países ainda prevalecem grandes lacunas de políticas de saúde e de programas de planejamento familiar, com maior concentração em regiões mais remotas e marginalizadas.

A Ásia Ocidental é representada pelos estudos com da Turquia com TFT de 2,4 e Israel com TFT de 3 filhos por mulher. Destaca-se, na Turquia, a existência de estremos: por um lado, uma população (mais escolarizada e de maior renda) com fecundidade baixa e preferências reprodutivas não atendidas, ou seja, com menos filhos do que o declarado ideal, compondo o denominado grupo de pós-transição da fecundidade; e, por outro, um grupo populacional (menos escolarizado e de menor renda) com fecundidade ainda acima da reposição e tendo mais filhos do que o desejado. Essas diferenças poderiam ser amenizadas com o processo de modernização, todavia, isso não é esperado, uma vez que não há uma convergência entre os grupos subpopulacionais. Já Israel, pela permanência dos elevados índices de fecundidade, é tratado como um caso enigmático. Os hábitos culturais familistas, religiosos e de pró-natalismo, as condições políticas e a grande heterogeneidade de composição de sua população seriam os principais responsáveis por esse comportamento atípico. Apesar da existência de grandes diferencias no comportamento de fecundidade e nas preferências reprodutivas nos distintos grupos socioeconômicos e religiosos, ainda não se têm os elementos necessários para explicar o comportamento diferenciado do país.

Finalmente, tem-se o sudeste da Ásia, que é a região com os maiores diferenciais de fecundidade (TFT de 1,2 a 5,9 filhos por mulher) e englobou o maior conjunto de países 
analisados na coletânea, com os casos de Brunei, Camboja, Indonésia, Malásia, Mianmar, Filipinas, Cingapura, Papua Nova Guiné e Timor Leste. Três países apresentam fecundidade abaixo do nível de reposição e um número de filhos desejados próximo de 2, ou seja, todos sofrem com o fenômeno da discrepância negativa de fecundidade. Brunei, com TFT de 1,7 filho por mulher, registra o menor gap de fecundidade. Já Cingapura e Coreia do Sul encontram-se em uma situação mais preocupante, com TFT de 1,5 e 1,24 filho por mulher, respectivamente, como reflexo de um acelerado processo de desenvolvimento econômico que acarretou mudanças nos custos e valores das crianças. Ambos apresentam características típicas da segunda transição demográfica e, mesmo com investimento em políticas de incentivo à natalidade, nas últimas décadas, não conseguem sair da armadilha da baixa fecundidade. 0 aumento da escolaridade feminina, a elevada inserção no mercado de trabalho e o custo de oportunidade do casamento, somados à pressão para criação dos filhos, tanto dos custos financeiros quanto emocionais da educação que recaem sobre os pais - sobretudo, para as mulheres -, são os principais fatores que impedem a realização das preferências reprodutivas nesses países. Possíveis medidas que alterem essas normas e facilitem a articulação trabalho e família podem contribuir para que os casais atinjam seus objetivos reprodutivos.

Indonésia e Camboja são países que apresentam TFT pouco acima da reposição - em torno de 2,4 filhos. Com diminuição no número de filhos desejados, ambos viram redução do gap entre fecundidade alcançada e desejada, a qual se situa entre 2,4 e 2,6. Apesar disso, permanecem diferenciais socioeconômicos e culturais importantes, que contribuíam para a existência de um percentual de 11\% de mulheres em 2014, no Camboja, que tinham mais filhos do que o declarado ideal. Esses países ainda têm alta demanda por métodos contraceptivos, uma vez que o uso de métodos tradicionais permanece elevado. 0 futuro da fecundidade vai depender da diminuição das desigualdades socioeconômicas, de políticas de acesso ao planejamento familiar e, no caso da Indonésia, da aceitação, por parte das gerações mais novas, do slogan "Dois filhos são suficientes".

Dois países com características próximas são Malásia e Filipinas, ambos com uma TFT próxima de 3 filhos por mulher. Nesse último observa-se uma aproximação entre a fecundidade alcançada e a desejada, devido, especialmente, à redução mais da fecundidade do que do número de filhos desejados, o qual permanece estável ao redor de 2,8. Os diferenciais de escolaridade, religião e das preferências por sexo dos filhos são fatores decisivos no delineamento dos níveis de fecundidade e preferências reprodutivas nesses países, estando esses níveis também em queda na Malásia. Para a maioria das mulheres, ainda é distante o alcance de suas preferências reprodutivas, em que prevalece a fecundidade discrepante positiva. É esperado que se tenham reduções substanciais da fecundidade nas próximas décadas, em função do contínuo empoderamento feminino, aumento da escolaridade, inserção no mercado de trabalho e adiamento do casamento e da maternidade, diminuindo as preferências por filhos. 
Myanmar, desde a sua independência, por ser densamente pouco povoado, tem implementado políticas de incentivo à natalidade, o que resulta em, mesmo com declínio da fecundidade, uma média de 3,7 filhos por mulher. 0 padrão de casamentos jovens é apontado como um determinante importante para as preferências reprodutivas e os níveis de fecundidade nesse país. Já em Papua Nova Guiné, apesar de também apresentar lento processo de transição da fecundidade (TFT de 4,4), destaca-se a importância do patriarcado. Esses países são marcados por diferencias regionais, educacionais e de saúde que influenciam diretamente o contexto de implementação das preferências reprodutivas. Mesmo que, recentemente, não tenha sido observada diminuição no número de filhos desejados em Papua Nova Guiné, assim como notado em Myanmar, a demanda por programas de planejamento familiar é elevada em ambos os casos. Recuos nos níveis de fecundidade no futuro serão influenciados, no caso de Myanmar, pelo aumento da escolaridade feminina e dificuldade de encontrar parceiros e, em Papua Nova Guiné, pelo empoderamento das mulheres nas suas decisões reprodutivas.

Com a maior fecundidade da Ásia, Timor-Leste é discutido no artigo 23, revelando algumas especificidades históricas (recente independência da Indonésia e conflitos étnicos), sociais e culturais que fazem com que a fecundidade desejada e a realizada sejam altas: o número ideal de filhos é 5 , sendo ainda maior entre os homens. Curiosamente, a preferência por limitar a fecundidade é mais intensa entre as mulheres de menor escolaridade do que entre as mais escolarizadas e é comum encontrar um número de filhos desejados elevado entre estas últimas. Os homens possuem forte influência nas decisões reprodutivas e a grande maioria não aprova o planejamento familiar, sendo a intenção de uso de contraceptivos baixa. Para além das diversas urgências no que envolvem políticas de saúde, redução da pobreza, geração de emprego e renda, acesso à comida de qualidade e a métodos contraceptivos que poderão desempenhar papéis importantes para redução dos níveis de fecundidade, são, principalmente, as mudanças nas práticas culturais que poderão frear o acelerado crescimento populacional do país.

Salienta-se que essa coletânea engloba um conteúdo bastante rico, que proporciona uma visão completa das tendências das preferências reprodutivas e da fecundidade para um contexto muito específico e complexo, referente aos países asiáticos. Os artigos mostram-se muito úteis aos estudiosos do tema, pois apresentam, revisam e criticam de forma muito cautelosa e esclarecedora conceitos, medidas e indicadores essenciais para a estimação e compreensão das preferências reprodutivas, fornecendo análises inéditas dos países estudados. Esse conhecimento acerca das preferências reprodutivas é importante, seja para estimar a demanda não atendida por planejamento da fecundidade e a fecundidade não alcançada, seja para prever o futuro da fecundidade.

Além disso, sabe-se que as preferências reprodutivas e a compreensão da perspectiva individual tornam-se, cada vez mais, importantes em contextos de transição da fecundidade. Como demostrando por Bongaarts e Casterline (2018), na maioria dos países em 
desenvolvimento, mesmo com a redução da fecundidade, é distante a realização das preferências reprodutivas, especialmente pela ocorrência das gravidezes indesejadas. Paralelamente, Casterline e Han (2017) demostram que, nestes mesmos países, também é comum a existência da fecundidade não realizada. Portanto, esse livro é um guia inspirador, servindo de estímulo para que trabalhos similares possam ser desenvolvidos acerca de outras regiões, notadamente nos países latino-americanos, em que muitos já possuem fecundidade abaixo do nível de reposição e sinalizam (CARVALHO; BONIFÁCIO; COSTA, 2020) uma tendência de substituição da discrepância positiva de fecundidade para a prevalência da fecundidade não realizada.

Dessa maneira, destaca-se a riqueza dos dados nos estudos aqui apresentados, que tiveram como principais fontes de informações a Demographic Health Surveys e Multiple Indicator Cluster Surveys. Pesquisas como estas são essenciais para a compreensão da complexidade das preferências reprodutivas. Nesse sentido, enfatiza-se a necessidade do Brasil, tal qual outros países latino-americanos, de avançar no desenvolvimento de bases de dados sobre a temática e/ou atualizar as pesquisas já existente, como é o caso da Pesquisa Nacional de Demografia e Saúde, cuja última edição ocorreu em 2006. Afinal, até quando vamos continuar no escuro sobre as tendências das preferências reprodutivas? Até quando não saberemos quão distantes estamos do alcance dos direitos reprodutivos?

\section{Referências}

BONGAARTS, J.; CASTERLINE, J. B. From fertility preferences to reproductive outcomes in the developing world. Population and Development Review, v. 44, n. 4, p. 793-809, Dec. 2018.

CARVALHO, A. A. D.; BONIFÁCIO, G. M. D. O.; COSTA, I. G. D. D. Panorama del déficit de fecundidad en América Latina a partir de dos indicadores. Notas de Población, n. 110, p. 127-156, enero-junio 2020.

CASTERLINE, J. B.; HAN, S. Unrealized fertility: fertility desires at the end of the reproductive career. Demographic Research, n. 36, p. 427-454, 2017.

\section{Sobre a autora}

Angelita Alves de Carvalho é pesquisadora em Informações Geográficas e Estatísticas pelo IBGE e professora permanente no Programa de Pós-graduação em População, Território e Estatísticas Públicas da Escola Nacional de Ciências Estatísticas (Ence/IBGE) e no Programa de Pós-graduação em Economia Doméstica da Universidade Federal de Viçosa (UFV).

\section{Endereço para correspondência}

Rua André Cavalcante, 106, sala 503C, Bairro de Fátima 20231-050 - Rio de Janeiro-RJ, Brasil 